\title{
Participação de um consórcio de alumínio no Brasil: um estudo de caso sobre ações
}

\section{sustentáveis}

\author{
Participation in an aluminum consortium in Brazil: a case study on sustainable actions
}

Recebido: 22/06/2021 | Revisado: 30/06/2021 | Aceito: 12/08/2021 | Publicado: 14/08/2021

\author{
Wandercleydson Pereira de Farias \\ ORCID: https://orcid.org/0000-0002-3077-6788 \\ Universidade Federal de Campina Grande, Brasil \\ E-mail: v.farias99@gmail.com \\ Isabel Lausanne Fontgalland \\ ORCID: https://orcid.org/0000-0002-0087-2840 \\ Universidade Federal de Campina Grande, Brasil \\ E-mail: isabelfontgalland@gmail.com
}

\begin{abstract}
Resumo
A Alumar (Consórcio de Alumínio do Maranhão S.A.), instalada em São Luís, é uma empresa formada por um consórcio entre as mineradoras transnacionais Alcoa, Rio Tinto e South32. É uma das maiores produtoras de alumina do mundo, e uma das maiores empresas instaladas no Maranhão. Era também uma grande produtora de alumínio, mas as atividades com o metal foram encerradas em março de 2015. A Alumar sempre esteve presente na vida econômica, social e cultural no estado. Investimentos, parcerias, pesquisas, geração de emprego e renda, qualificação profissional e ações sustentáveis na fabricação da alumina deram à Alumar, ao longo dessas quatro décadas, seu caráter de liderança no segmento. De maneira ativa e participativa, a Alumar conquistou excelência operacional por meio do absoluto respeito pela vida, diversidade, meio ambiente e sustentabilidade, além de intensa participação nas comunidades com foco nas áreas da educação, geração de emprego e renda e engajamento. O presente estudo de caso, tem por objetivo apresentar as principais características da trajetória deste consórcio e a sua importância para o desenvolvimento industrial local.
\end{abstract}

Palavras-chave: Alumar; Consórcio; Indústria; Economia.

\begin{abstract}
Alumar (Consórcio de Alumínio do Maranhão S.A.), installed in São Luís, is a company formed by a consortium between the transnational mining companies Alcoa, South 32 and Alcan. It is one of the largest producers of alumina in the world, and one of the largest companies installed in Maranhão. It was also a large producer of aluminum, but the activities with the metal ended in March 2015. Alumar has always been present in the economic, social and cultural life in the state. Investments, partnerships, research, job and income generation, professional qualification and sustainable actions in the manufacture of alumina have given Alumar, throughout these four decades, its leadership character in the segment. In an active and participatory way, Alumar has achieved operational excellence through absolute respect for life, diversity, the environment and sustainability, in addition to intense participation in communities with a focus on the areas of education, job and income generation and engagement. The present case study aims to present the main characteristics of the trajectory of this consortium and its importance for local industrial development.
\end{abstract}

Keywords: Alumar; Consortium; Industry; Economy.

\section{Introdução}

Em meados da década de 1980, em meio a dificuldades políticas e econômicas, o governo aprovou o projeto de instalação da fábrica de alumínio da Alcoa Alumínio SA na Ilha de São Luís, Brasil. A localização da fábrica foi escolhida por ser de potencial estratégico, apresentando vantagem portuária e grande suprimento de energia da Usina de Tucuruí. A Alumar constituiu-se então como grande pólo de vantagens tecnológicas sendo uma poderosa alavanca de produção de mão de obra qualificada empregando cerca de 15000 técnicos e engenheiros das mais diversas áreas.

O porto foi a primeira parte do complexo a entrar em operação e, em março de 1984, recebeu o primeiro lote de bauxita e posteriormente outros compostos foram introduzidos. A refinaria entrou em operação pela primeira vez em maio de 1984 e, 
em julho do mesmo ano, a Redução produziu sua primeira tonelada de metal. A Alumar foi oficialmente inaugurada em 16 de agosto de 1984 .

De maneira ativa e participativa, a Alumar conquistou excelência operacional por meio do absoluto respeito pela vida, diversidade, meio ambiente e sustentabilidade, além de intensa participação nas comunidades com foco nas áreas da educação, geração de emprego e renda e engajamento. O presente estudo de caso, tem por objetivo apresentar as principais características da trajetória deste consórcio e a sua importância para o desenvolvimento industrial local.

Figura 1 - Porto da Alumar.

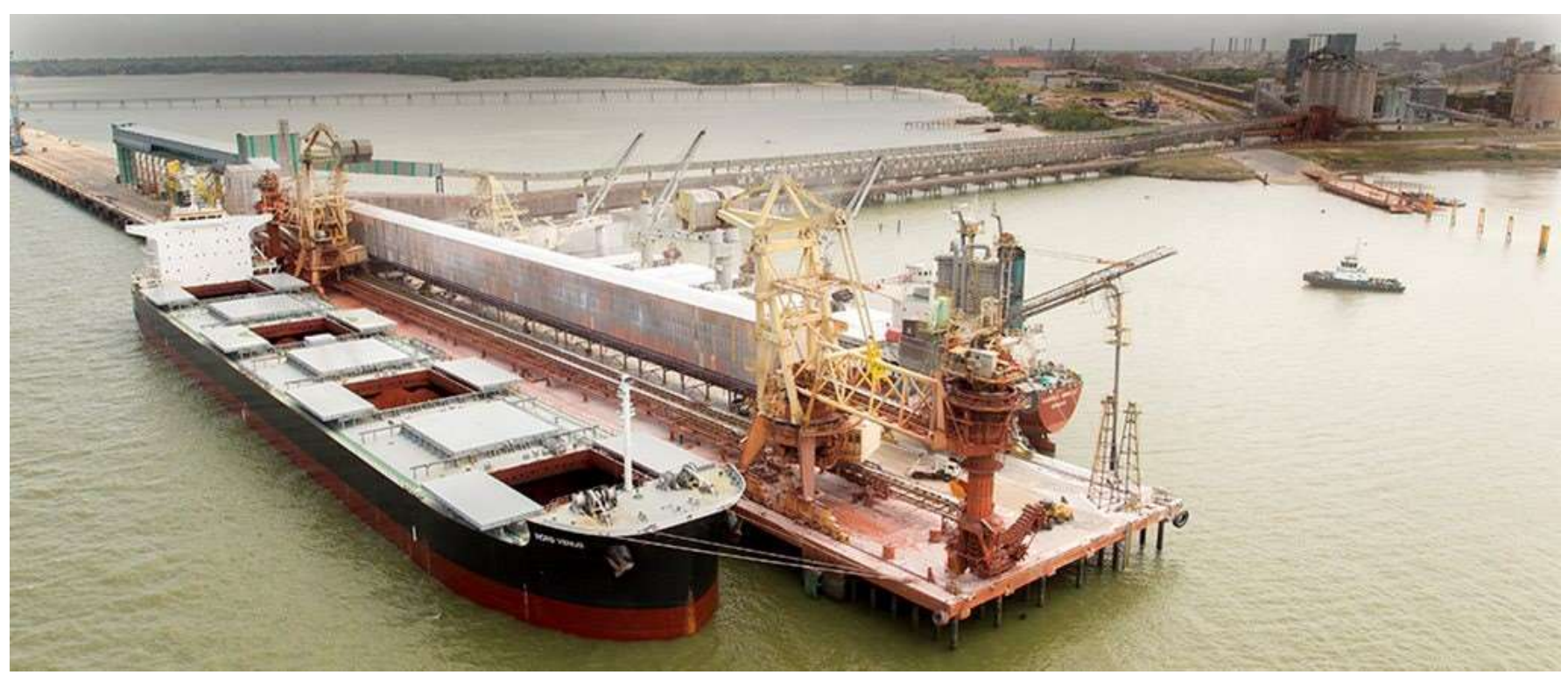

Fonte: Acervo Alumar (2021).

O Parque Ambiental da Alumar possui 1.800 hectares, tendo sido inaugurado em 1996, sendo composto de manguezais, capoeiras, várzeas e brejos, abrigando diversas espécies de animais. Também é composto por um prédio administrativo, um prédio para oficinas de educação ambiental, alojamento para pesquisadores, anfiteatro, trilha, mirante, viveiro de mudas, área de compostagem e estacionamento para visitantes. Com o objetivo de preservar, conservar e promover um espaço social, cultural, técnico, científico e educacional, recebe anualmente milhares de visitantes demonstrando a capacidade que a indústria moderna tem de ser sustentável e contribuir para a integração do homem à natureza.

\section{Metodologia}

O presente estudo pode ser classificado como sendo um estudo de caso, uma vez que se descreve o caso do desenvolvimento de um consórcio de mineradoras transnacionais, bem como as características de sua atuação.

\section{Resultados e Discussão}

\subsection{Produção}

A bauxita chega através do porto e é trazida de minas em Trombetas e Juruti, no oeste do Pará. Na Refinaria, o minério é submetido ao processo Bayer, através do qual se obtém a alumina após uma série de reações em solução aquosa. Ao fim deste processo, é formado um resíduo poluente denominado lama vermelha, que pode trazer sérios prejuízos ao meio ambiente se não 
for disposto de maneira adequada. Na Redução, a alumina passava pelo processo Hall-Héroult dentro das cubas, sendo obtido alumínio metálico através de eletrólise. Também através do porto, a produção da planta da Alumar é escoada.

Desde 2013, a Alumar vem reduzindo a produção de alumínio no Brasil como parte de um plano global de cortes de gastos. A empresa havia paralisado a redução em sua unidade em Poços de Caldas em 2014. Em março de 2015, foi cortada a produção restante de 74 mil toneladas de alumínio na planta de São Luís, encerrando a fabricação do metal pela empresa no país. A Redução na unidade foi fechada e 650 funcionários foram demitidos, entretanto, as atividades com alumina não foram afetadas. Com o projeto de expansão da Refinaria, em 2009, a planta triplicou a produção de alumina, hoje, com um volume de 3.7 mil toneladas /ano.

Quadro 1 - Produção da Alumar (em milhares de toneladas).

\begin{tabular}{|c|c|c|c|c|c|c|c|c|c|c|}
\hline & 2011 & 2012 & 2013 & 2014 & 2015 & 2016 & 2017 & 2018 & 2019 & 2020 \\
\hline Alumina & 3971,5 & 3.398 .2 & 3.442 .2 & $3.699,3$ & 3.671 .8 & 3.715 .92 & 3.695 .5 & 3.512 .0 & $3.671,7$ & 3.850 .0 \\
\hline Aluminio primario & 438,3 & 402.4 & 339,5 & 167,0 & 34.8 & - & - & - & - \\
\hline
\end{tabular}

Fonte: Associação Brasileira do Alumínio (ABAL).

Movimentação do Porto Alumar: Matérias-primas, insumos, alumina e bauxita: 14.500 .000 toneladas por ano.

Na Refinaria é realizado o processo de transformação da bauxita em alumina, ou óxido de alumínio. Todo o processo de produção é computadorizado, garantindo economia e eficiência. Parte da matéria-prima é reaproveitada no processo da Refinaria. Os resíduos são depositados em locais especialmente preparados para sua contenção - Áreas de Disposição de Resíduos de Bauxita, que, após atingir sua capacidade de utilização, são reabilitadas.

\subsection{Influência Econômica}

O Maranhão viu sua economia ganhar um novo impulso com a instalação da Alumar, ao receber um dos maiores projetos privados na área industrial até então implantado no país. O investimento total na planta, desde a inauguração, ultrapassa os US\$ 5.4 bilhões propiciando, sobretudo aos maranhenses, capacitação profissional, emprego e oportunidades de negócios. A fábrica, entre operação e projeto, totaliza 3.500 colaboradores diretos e indiretos e destes, aproximadamente, $90 \%$ são maranhenses.

Entre os colaboradores diretos, a Alumar conta com 173 mulheres entre colaboradoras, estagiárias e aprendizes, com 87\% maranhenses. Destas, 25 em cargos de liderança. Na expansão da Refinaria, inaugurada em 2009, foram investidos US\$ 2.7 bilhões, elevando a capacidade anual de operação de 1.5 milhão toneladas para 3.7 milhões de toneladas. Em 2019, as operações da Alumar contribuíram com, aproximadamente, R\$ 146 milhões para os governos federal, estadual e local por meio do pagamento de impostos, royalties, taxas e encargos. 
Figura 2 - Usina da Alumar.

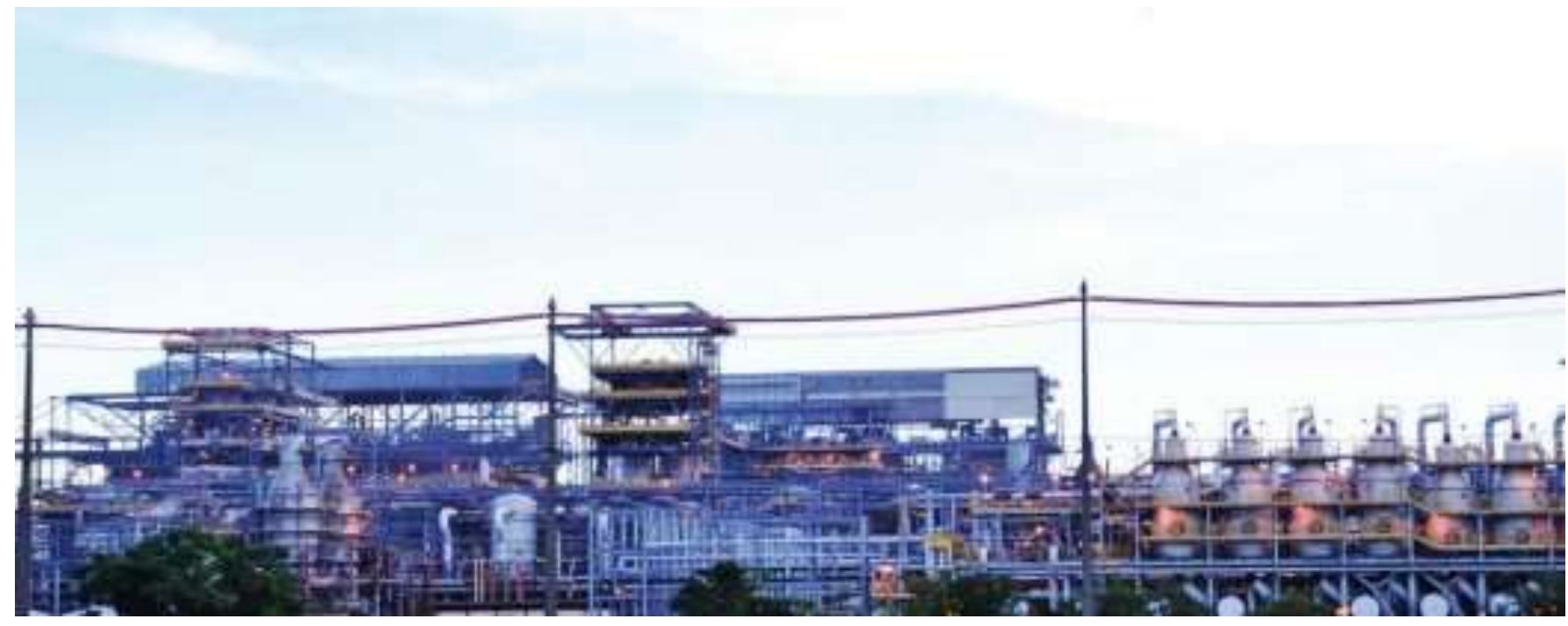

Fonte: Acervo Alumar (2019).

\subsection{Capital Humano e Relacionamento Comunitário}

A Alumar reconhece em suas pessoas a razão de seu sucesso. O Consórcio promove a gestão da diversidade e incentiva uma cultura de estímulo ao conhecimento e de inclusão. Tem hoje em seu efetivo cerca de $90 \%$ de mão de obra maranhense e tem trabalhado junto às empresas prestadoras de serviços para garantir que grande parte dos colaboradores que atuam nas áreas da fábrica sejam moradores das comunidades vizinhas à planta. Esse número expressivo confirma o compromisso e apoio ao desenvolvimento local.

Consciente de sua responsabilidade social e de forma a reter talentos, a Alumar se destaca investindo em pessoas e criando canais e oportunidades para aprimorar as habilidades e conhecimentos de seus colaboradores e prestadores de serviços. Internamente, investe fortemente na capacitação de seus profissionais, treinando, capacitando e incentivando-os à educação continuada, aprendizagens e aperfeiçoamento profissional, na medida que buscam novas especializações e o domínio de outras línguas.

Figura 4 - Profissionais da Alumar.

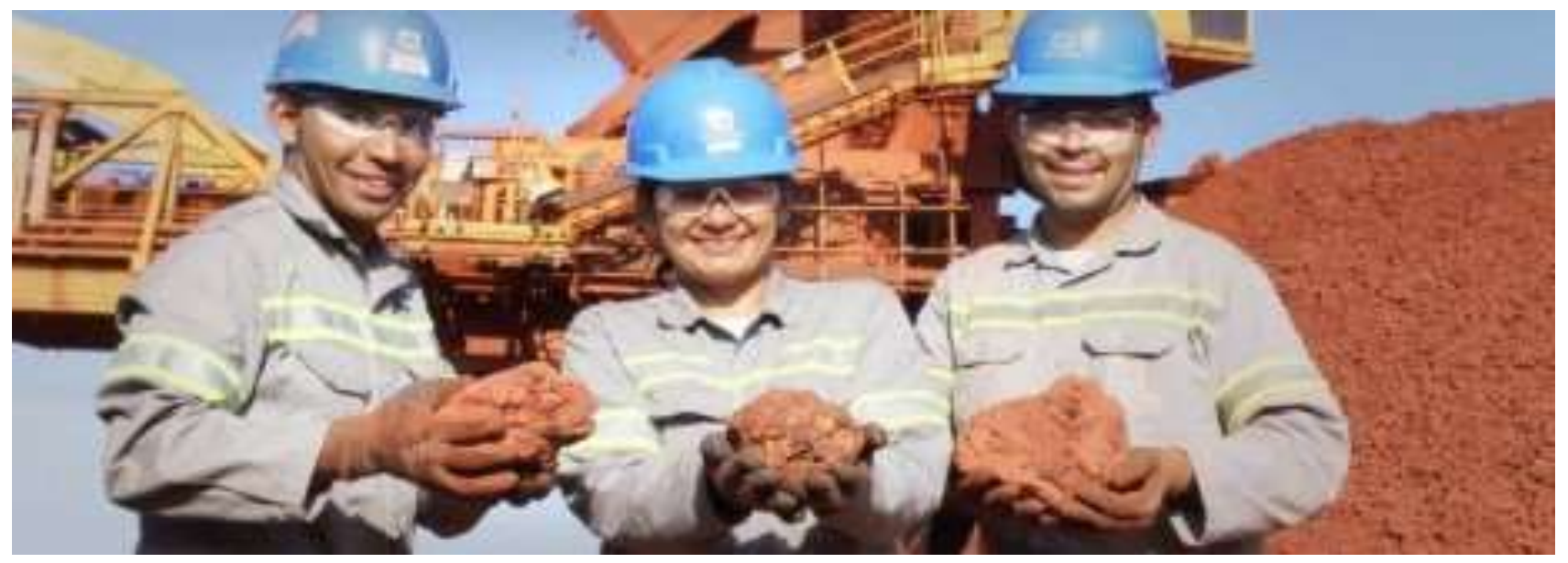

Fonte: Acervo Alumar (2019). 
Com o objetivo de promover o desenvolvimento social das comunidades, a Alumar investe em diversas áreas como educação, atenção básica à saúde, programas de conservação e educação ambiental que, aliadas à formação e atividades de capacitação profissional de jovens e adultos, contribuem para a melhoria da qualidade de vida dos moradores das comunidades vizinhas e de São Luís.

\subsection{Sustentabilidade e Meio Ambiente}

Destaca-se, ainda, pela conservação de ecossistemas, pela reabilitação de áreas utilizadas para fins industriais e pela transformação de seu Complexo Industrial e de suas áreas de Disposição de Resíduos de Bauxita em verdadeiros laboratórios de pesquisa e desenvolvimento de novas tecnologias ambientais. O Consórcio possui um sistema de gestão integrado que engloba a gestão de qualidade, saúde, segurança, meio ambiente, gestão social e foi estabelecido com base nas normas NBR ISO 9001, NBR ISO 14001 e OHSAS 18001. Em 2019, obteve a certificação ASI, (Aluminium Stewardship Iniative), o mais importante Selo de Sustentabilidade na cadeia de valor do alumínio, onde atesta o trabalho consistente da empresa em produzir alumina de forma responsável e sustentável.

A Hydro CIRCAL é a marca de alumínio reciclado premium feito com um mínimo de 75\% de sucata de alumínio pósconsumo reciclado. Usando alumínio reciclado, reduzimos drasticamente o uso de energia na fase de produção, ao mesmo tempo em que não se perde em qualidade. O conteúdo real de sucata reciclada pós-consumo varia, mas garantimos um mínimo de $75 \%$. O uso de sucata pós-consumo, que já viveu em um produto, nos permite reduzir a pegada de carbono para 2,3 quilos de CO2e por quilo de alumínio produzido.

Figura 5 - A. Minério e B. Alumina.
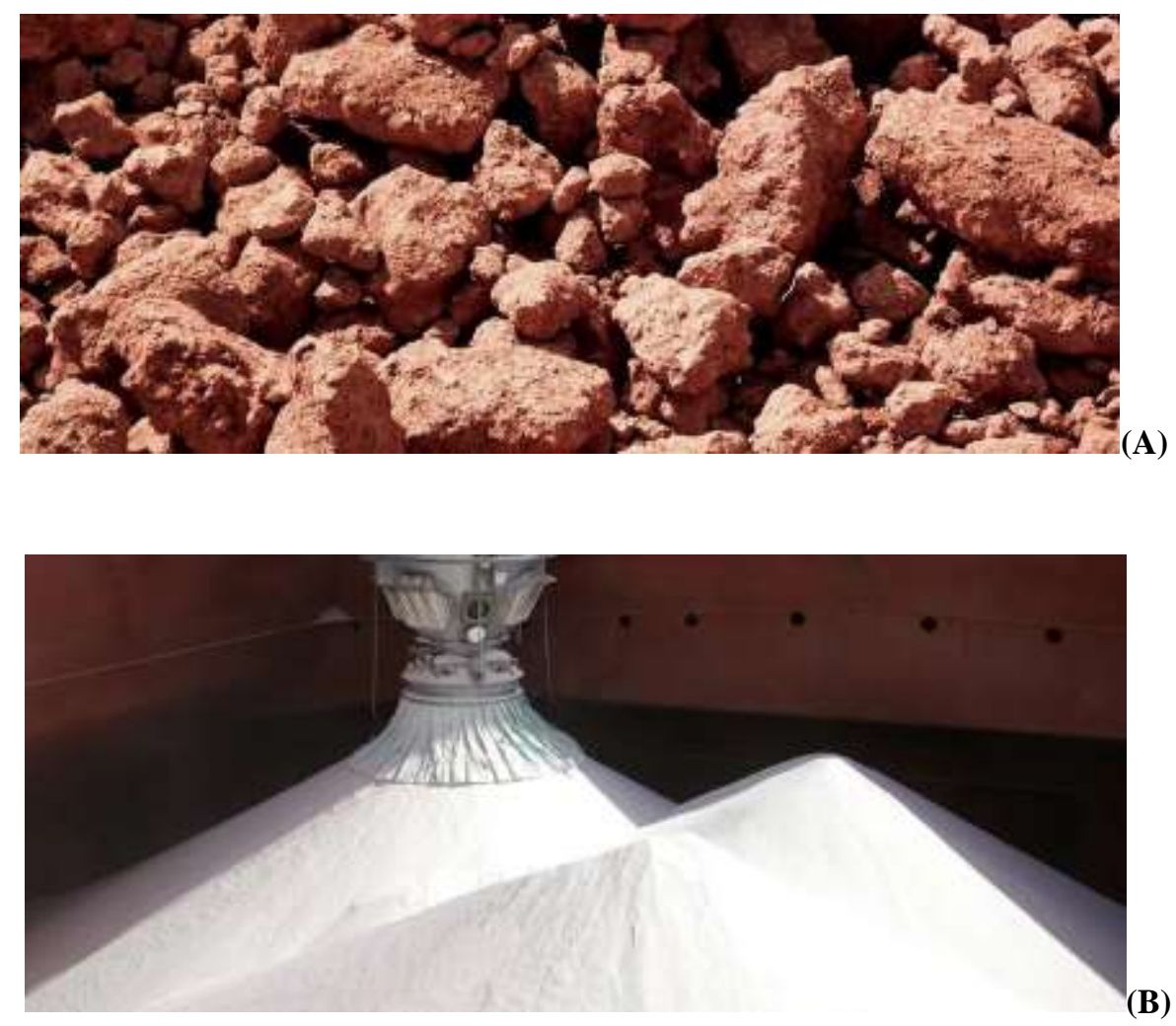

Fonte: Acervo Alumar (2000). 
A matéria-prima necessária para a produção do alumínio primário é o óxido de alumínio, também chamado de alumina. É um pó branco produzido pelo refino da bauxita. São necessárias cerca de duas toneladas de alumina para produzir uma tonelada de alumínio por meio de um processo eletrolítico. A alumina também é usada para vários outros fins, como purificação de água e como aditivo em várias aplicações. A Hydro produz alumina na Hydro Alunorte no Brasil, a maior refinaria de alumina do mundo. Parte disso é usado como base para a produção de alumínio da própria Hydro, mas muito é vendido para outras empresas. Além disso, o Grupo Rio Tinto possui a política de publicar externamente os dados da produção de gases de efeito estufa e outras emissões atmosféricas, resíduos e rejeitos, juntamente com as práticas de gestão de água do Grupo. Por isso, estão entre os mais transparentes do setor em relação aos riscos hídricos e permanecem focados em demonstrar cada vez mais o bom desempenho ambiental por meio de dados e tecnologia

\section{Considerações Finais}

O Consórcio de Alumínio do Brasil (Alumar) é um dos maiores complexos industriais de produção de alumina e alumínio do mundo. Inaugurado em julho de 1984, é formado pelas empresas Alcoa, Rio Tinto e South32 e desempenha um papel importante no Maranhão. Cerca de $90 \%$ de seus colaboradores são maranhenses, além de contar com centenas de fornecedores locais e estar colocada entre as empresas de mais alta reputação nos mercados mundiais; um compromisso com uma produção capaz de suprir as demandas operacionais, sem comprometer os recursos necessários para o abastecimento futuro, uma sintonia entre sucesso econômico, conservação ambiental e responsabilidade social.

O Consórcio Alumar ajudou a transformar o estado do Maranhão. Criou milhares de empregos diretos e indiretos e incentivou a diversificação da economia regional. Consciente de sua responsabilidade social e de forma a reter talentos, a Alumar se destaca investindo em pessoas e criando canais e oportunidades para aprimorar as habilidades e conhecimentos de seus colaboradores e prestadores de serviços. Consciente de sua responsabilidade social e de forma a reter talentos, a Alumar se destaca investindo em pessoas e criando canais e oportunidades para aprimorar as habilidades e conhecimentos de seus colaboradores e prestadores de serviços. O Consórcio possui um sistema de gestão integrado que engloba a gestão de qualidade, saúde, segurança, meio ambiente, gestão social e foi estabelecido com base nas normas NBR ISO 9001 , NBR ISO 14001 e OHSAS 18001, os quais lhe garantem reconhecimento pelos processos baseados em sustentabilidade ambiental.

\section{Referências}

Associação Brasileira do Alumínio (ABAL). (2021). «Estatísticas nacionais - Alumar».

Aberta para novos desafios, a Alumar (2021). celebra 40 anos de implantação em São Luís. Disponível em: https:/g1.globo.com/ma/maranhao/especialpublicitario/alumar/noticia/2020/08/14/aberta-para novos-desafios-a-alumar-celebra-40-anos-de-implantacao-em-sao-luis.html.

Alcoa (2021). Report of Sustainability https://www.alcoa.com/sustainability/en/case-studies/releases?id=2021/04/a-drive-for-safety.

Agenda of Sustanability (2021). https://www.bloomberg.com/https://www.bloomberg.com/news/articles/2021

Alumar bate recorde diário de produção de alumina. (2021). https://www.noticiasdemineracao.com/produ\%C3\%A7\%C3\%A3o/news/1403170/alumar-bate recorde-di\%C3\%A1rio-de-produ\%C3\%A7\%C3\%A3o-de-alumina.

Brasil (2021). alumar-fact-sheet.pdf. https://www.alcoa.com/brasil/pt/pdf/brasil-alumar fact-sheet.pdf.

Charles; S., \& Susan C. The Oxford Handbook of Compartive Politics .Oxford. Oxford University Press.

Economia industrial: fundamentos teóricos e práticas no Brasil / organizadores, David Kupfer e Lia Hasenclever. (2.ed.) Elsevier, 2013.

Gerring, John. 2004. What is a case study and what it is good for?,American Political Science Review, 98(2), 341-354. 
e-Acadêmica, v. 2, n. 2, e072230, 2021

(CC BY 4.0) | ISSN 2675-8539 | DOI: http://dx.doi.org/10.52076/eacad-v2i2.30

Gerring, John. 2007 Case study research. New York: Cambridge University Press.

Gerring, John. 2009. The Case Study: what it is and what it does. In: BOIX, 